\title{
EFFECTS OF DIETARY INCLUSION OF CHLORELLA VULGARIS ON GROWTH, BLOOD BIOCHEMICAL PARAMETERS AND ANTIOXIDANT ENZYMES ACTIVITY IN OLIVE FLOUNDER, PARALICHTHYS OLIVACEUS
}

\author{
Samad Rahimnejad ${ }^{1}$, Heum-Gi Park ${ }^{2}$, Sang-Min Lee ${ }^{1 *}$ \\ Department of Marine Bioscience and Technology, Gangneung-Wonju National University, \\ Gangneung 25457, Korea \\ Department of Marine Resource Development, Gangneung-Wonju National University, Gangneung \\ 25457, Korea
}

\begin{abstract}
This study was carried out to investigate the effects of dietary inclusion of defatted Chlorella on growth performance, body composition, blood biochemistry and antioxidant enzymes activity in olive flounder. Four isonitrogenous ( $51 \%$ crude protein) diets were formulated to contain 0 (control), 5, 10 or 15\% Chlorella meal (CM) (designated as, Con, CM5, CM10 and CM15, respectively) and fed to triplicate groups of fish (104.4 g) to apparent satiation twice daily for $8 \mathrm{wk}$. At the end of feeding trial, significant enhancement $(P<0.05)$ in growth performance was obtained at over $10 \% \mathrm{CM}$ compared to fish fed the control diet. No significant changes in dorsal muscle and liver proximate compositions were found following $\mathrm{CM}$ administration. The groups fed $\mathrm{CM}$ containing diets revealed significantly lower plasma cholesterol concentration than those fed the control diet. Dietary CM affected antioxidant enzymes activity; significantly higher plasma catalase activity was found in fish fed $\geq 10 \%$ CM and total antioxidant capacity increased in CM5 and CM10 groups compared to control. However, plasma glutathione peroxidase and superoxide dismutase activities were not significantly influenced by dietary CM. Also, significant enhancement in DPPH radical scavenging activity was found in dorsal muscle of fish fed CM15 diet compared to control. The findings in this study showed that dietary inclusion of 10-15\% CM can enhance growth performance, and affect antioxidant enzymes activity and lipid metabolism in olive flounder.
\end{abstract}

\section{KEY WORDS}

Olive flounder, Chlorella vulgaris, Growth, Body composition, antioxidant activity

${ }^{*}$ Corresponding author: Tel.: +82 33640 2414; Fax: +82 336402955. 
E-mail address: smlee@gwnu.ac.kr 